\title{
Machine Learning Models: Learning Algorithms in Crime Investigation
}

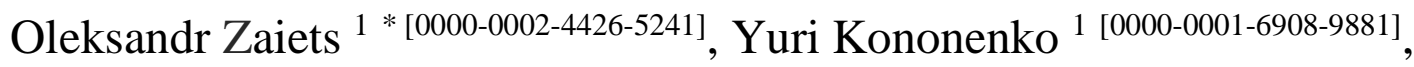 \\ Sergey Yeskov ${ }^{2}$ \\ ${ }^{1}$ Odesa State University of Internal Affairs, Odesa, Ukraine \\ ${ }^{2}$ Centre for European Reforms Studies, a.s.b.l. Grand Duchy of Luxembourg \\ *zaec_1985@meta.ua
}

\begin{abstract}
This article introduces machine learning, which is all around you, although you may not even know it. Thanks to machine learning, the search engine understands what results (and advertising) to display in response to your query. When you scan your mail, most of the spam passes you by because it has been filtered out by machine learning. If you decide to buy something on Rozetka.com.ua or watch YouTube to watch a movie, the machine learning system will helpfully offer options that you may like. With machine learning, Facebook decides what news to show you, and Twitter selects the appropriate tweets. Every time you use a computer, machine learning is involved. The only way to get the computer to do something is to write an algorithm that carefully explains to the machine what is required of it. However, machine learning algorithms guess everything themselves, drawing conclusions from the data, and the more data, the better they become. Computers don't need to be programmed; they program themselves. Artificial intelligence techniques have proven to be a promising tool in crime investigation. With the help of these methods, effective diagnostic and predictive tools can be developed to detect various crimes. In the future, artificial intelligence programs may become an integral part of the investigation of crimes. The police must be proactive in understanding theories of artificial intelligence and its usefulness in investigating crimes.
\end{abstract}

Keywords: deep learning, machine learning, artificial intelligence, crime investigation, learning algorithms.

\section{INTRODUCTION}

In the world, machine learning and artificial intelligence have become a popular topic both inside and outside the scientific discourse. A large number of scientific articles are devoted to the topics of machine learning and artificial intelligence. The terms are very related but not interchangeable. As the amount of data that becomes available increases, data mining will become even more prevalent as a prerequisite for technological advancement. [1, p. 3] Much of machine learning is about reducing a set of fairly disparate tasks to a set of fairly narrow, specific actions. Much of the science of machine learning is about solving these problems and providing reliable guarantees for solving them.

Machine learning is a field that specializes in the teaching aspect of artificial intelligence.

Machine learning - a section of the theory of artificial intelligence, the subject of which is the search for methods of solving problems by learning in the process of solving such problems. [2]

Machine learning is all around you, although you may not even know it. Thanks to machine learning, the search engine understands what results (and advertising) to display in response to your query. When you scan your mail, most of the spam passes you by because it has been filtered out by machine learning. If you decide to buy something on Rozetka.com.ua or watch YouTube to watch a movie, the machine learning system will helpfully offer options that you may like. Using Facebook's machine learning, Instagram decides which news to show you, and Twitter chooses the tweets that match. Whenever you use a computer, it is very likely that machine learning is involved somewhere.

The only way to get the computer to do something is to write an algorithm that carefully explains to the machine what is required of it. However, machine learning algorithms guess everything themselves, drawing conclusions from the data, and the more data, the 
better they become. This means that computers do not need to be programmed: they program themselves. [3, 4].

\section{RESEARCH METHODOLOGY}

We searched PubMed and Mecs-press for articles on leading artificial intelligence techniques used in crime investigation. The purpose of the scholarly article was to provide non-technical readers with a non-professional explanation of the machine learning methods used in legal science today.

\section{RESEARCH RESULTS}

Society changes with each new algorithm. Machine learning is changing science, technology, business, politics and other areas of life. Satellites and particle accelerators are increasingly exploring nature, and learning algorithms are transforming data streams into new scientific knowledge. The election is won by candidates who can better model voter behavior (for example, Trump v. Biden). Unmanned vehicles are conquering land, water and air. [5, 6] No one enters information about our tastes into Amazon's referral system: the learning algorithm determines them independently, summarizing information about purchases made. Google's remote car has learned not to go off the road on its own: no engineer has written an algorithm for it that explains step by step how to get from point $\mathrm{A}$ to point $\mathrm{B}$. No one knows how to write a program to drive a car. A car equipped with a learning algorithm will look at the driver's actions and understand itself [7].

We live in an age of algorithms. A few generations ago, the word "algorithm" would have caused most people only misunderstandings. Today, algorithms have penetrated into all corners of our civilization. They are sewn into everyday life and have found a place not only in mobile phones and laptops, but also in cars, apartments, appliances and toys. [8] So the bank is a giant tangle of algorithms, and people are only slightly adjusting the settings. Algorithms plan flights and then fly on airplanes. Algorithms control production, trade, supply, calculate revenue and keep accounts. If all algorithms suddenly stop working, the end of the world will come as we know it.

Computer algorithms are a sequence of actions that dictate their commands to the computer. Computers are made up of billions of transistor switches, and algorithms turn those switches on and off once a second.

To send a command to the computer, the simplest algorithm is to "push the switch". The position of one transistor is one unit of information: "one" if the transistor is on, and "zero" if it is off. [9] Someone on the bank's computers reports if you have exceeded your credit. Another unit in the bowels of the Social Security Administration tells you whether you are alive or dead.
The second simplest algorithm is "connection of two bits". Claude Shannon [10, p. 10-21], the recognized father of information theory, was the first to realize that switching transistors on and off in response to other transistors is essentially a logical conclusion. (He devoted this topic to his dissertation at the Massachusetts Institute of Technology, the most important thesis in history.) "Transistor A turns on only when transistors B and $\mathrm{C}$ are on" is the logic of a computer algorithm. "A turns on when $\mathrm{B}$ or $\mathrm{C}$ is on" is another logic. " $\mathrm{A}$ is on when B is off, and vice versa" is the simple logic of the computer. Any algorithm, no matter how complicated it may be, comes down to three operations: and, or and not. Using special symbols for these operations, you can represent simple algorithms in the form of diagrams.

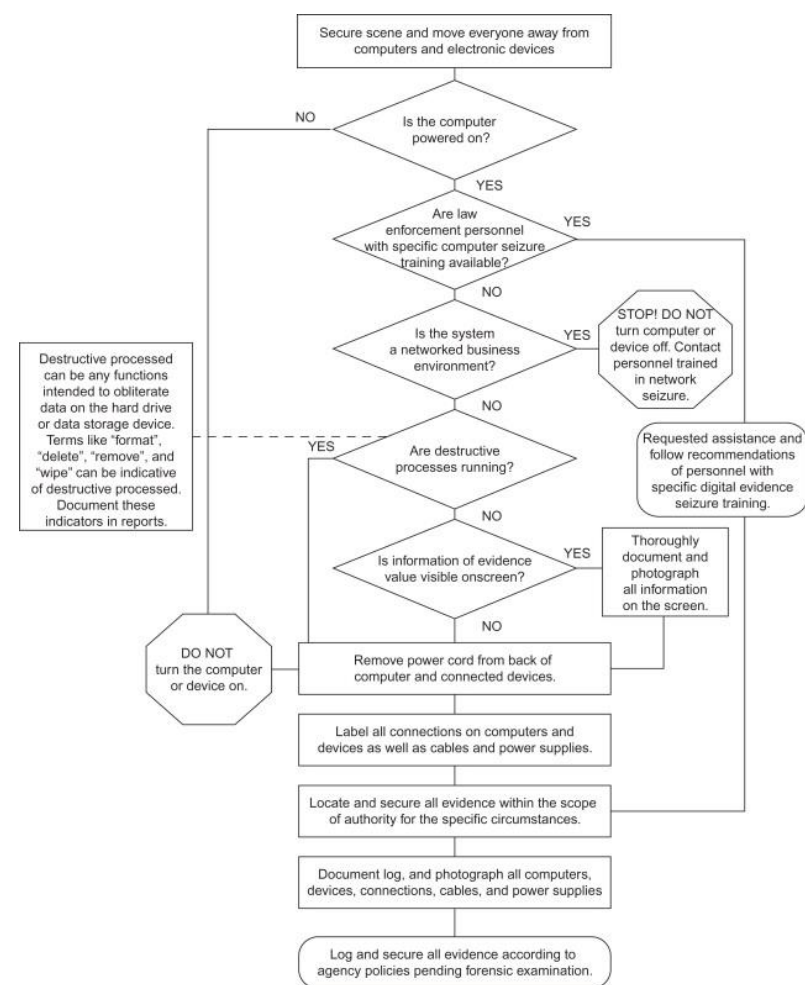

Figure 1 An example algorithms in the form of diagrams

All algorithms have input and output data: the data goes to the computer, the algorithm processes them and provides the result. Machine learning takes everything back: having data and the desired result, it creates an algorithm that transforms into one another. [11] Learning algorithms are those that create other algorithms learned by the data. With machine learning, computers write their own programs and algorithms.

The more data we have, the more we can learn. There is no data? Then there is nothing to learn. A lot of information? A huge field for learning. This is why machine learning is making a name for itself wherever exponentially growing amounts of data emerge.

Machine learning is a tool that can decapitate the giant of complexity. If you give a tutorial only a couple of hundred lines long with enough data, it will not only 
easily generate a program of millions of lines of code, but will also be able to do it again and again for different problems. [12] The simplification of the task for the programmer is phenomenal. Of course, the complexity of the processes will increase, but they will be smaller and will not grow immediately, so we will still have a big advantage. [13]

Computer learning algorithms allow you to accumulate both knowledge and skills. In machine learning, knowledge is often presented in the form of statistical models, because knowledge itself is, in fact, statistics. Skills are often a set of habits: if the road turns left, turn the steering wheel to the left. If there is an obstacle in front of you, apply the brakes. The procedure is often quite simple, although the knowledge involved is complex. Spam should be sent to the trash, but first you need to learn to distinguish it from regular emails. If you find out which position on the chessboard is successful, it becomes clear which movement to make (the one that will lead to the best position).

Machine learning has so many elements of systematic data collection: pattern recognition, statistical modeling, data mining, knowledge discovery, predictive analytics, data science, video analytics, systems analysis, and more. $[14,15,16]$ They all find their application and have different associations. Some live long and some do not. All this diversity is called machine learning.

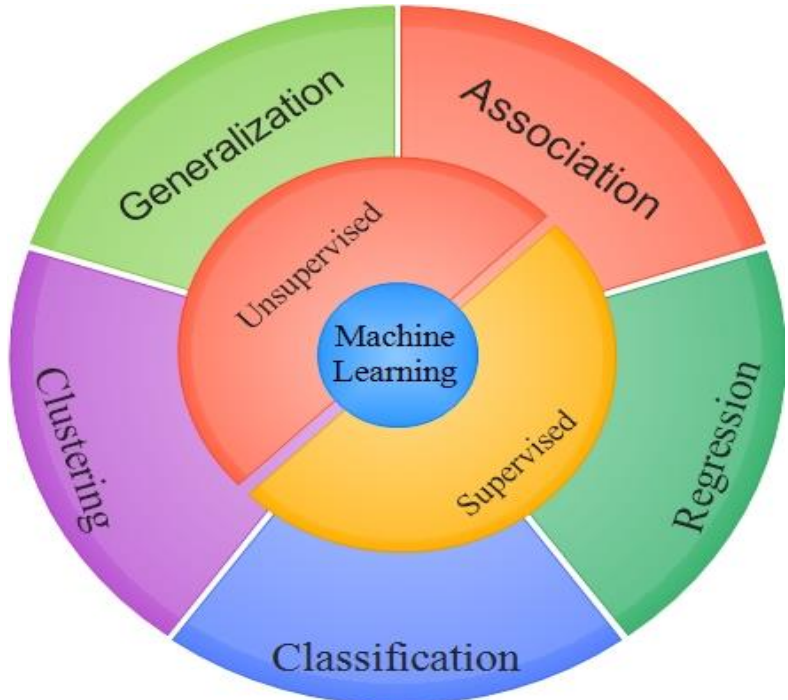

Figure 2 Building Blocks of Machine Learning

\section{DISCUSSION OF RESULTS}

The industrial revolution automated manual labor, the information revolution did the same with mental labor, and automated machine learning automation itself. Without this programming, it would be a bottleneck that would hinder progress. If you are a lazy and not very smart computer scientist, machine learning is an ideal specialty for you, because learning algorithms do all the work yourself, and you will receive only laurels. $[17,18]$
On the other hand, learning algorithms can leave us unemployed.

By raising automation to unprecedented heights, the machine learning revolution will bring about tremendous changes in the economy and society, such as the Internet, personal computers, machines, and the steam engine.

Many machine learning algorithms are used in crime investigation. Here are some of the most popular to date.

\section{Linear regression}

Linear regression is the simplest machine learning algorithm. The main idea of regression analysis is to determine the relationship between one or more numeric attributes and one numeric target. [8, 9, 19, 20] Linear regression is an analysis technique used to solve a regression problem using a straight line to describe a dataset.

\section{Logistic regression}

Logistic regression is a classification algorithm that aims to find a relationship between features and the likelihood of a particular outcome. Rather than using a straight line from linear regression to estimate the likelihood of a class, logistic regression uses a sigmoidal curve to estimate the likelihood of a class.

\section{Decision tree}

Decision tree is a guided learning technique that is mainly used for classification problems, but can also be used for regression. [6,7] The decision tree starts at the root node, the first decision point for splitting the dataset, and contains the only function that best splits the data into appropriate classes. [6, 7]

\section{Game AI}

Artificial intelligence is a set of software techniques used in computer games to create the illusion of intelligence in the behavior of computer-controlled characters. The game AI [21], in addition to the methods of traditional artificial intelligence, also includes algorithms for control theory, robotics, computer graphics and computer science in general.

\section{Acquisition of skills}

Skills acquisition is the science that underlies movement learning and performance, and is more commonly referred to as motor learning and control (Williams \& Ford, 2009). [22] Each stage embodies unique characteristics in terms of the athlete's level of performance of a skill or activity.

\section{The structure of discourse}

Discourse structure is a term used to describe how a whole text is organized - for example, how language is used in a poem, in a newspaper article, or in a speech intended to be read aloud. 


\section{Visualization of big data}

Big data visualization is the process of displaying data on charts, graphs, maps, and other visual forms. It is used to help people easily understand and interpret their data at a glance, as well as clearly show the trends and patterns that arise from this data.

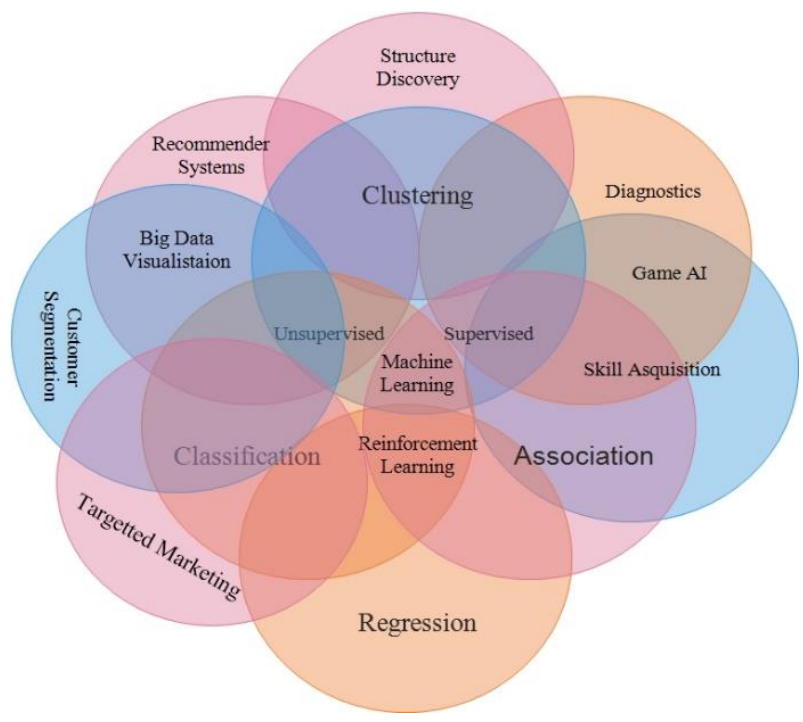

Figure 3 Machine learning methods

Machine learning is an artificial intelligence technique that does not directly solve a problem, but rather learns using solutions to many similar problems. $[23,24]$ To construct such methods, the tools of mathematical statistics, numerical methods, mathematical analysis, optimization methods, probability theory, graph theory, various methods of working with data in digital form are used.

There are two types of training:

Case studies, or inductive learning, is to identify empirical patterns in the data.

Deductive learning involves formalizing the knowledge of experts and transferring it to a computer in the form of a knowledge base. Deductive learning is commonly referred to as expert systems. [25]

Inductive learning methods have been developed as an alternative to classical statistical approaches. Many methods are closely related to information retrieval (information retrieval), data extraction [26, 27, 28].

Effective processing of forensically significant information in the disclosure and investigation of crimes is equally necessary for an investigator and an employee of an inquiry agency, an expert and a specialist. Along with individual characteristics, their professional activity carries the characteristic features of the most general order. While doing their work, they solve practically the same problems, perform the same actions, which, as a rule, are complex in nature, and this means a certain similarity. Consequently, on the basis of studying the patterns of their practical activities and generalizing best practices, it is possible to identify the optimal sequence of actions of these subjects in typical investigative situations in order to present it for further use in the form of forensic algorithms and investigation programs.

Theoretical comprehension of these and many other problems of algorithmization and programming against the background of their step-by-step solution will lead to a significant increase in the usefulness of methodological recommendations. The need for them to be maximally oriented towards the needs of practice should be emphasized.

The experience gained by investigating crimes led to the need to systematize and typify the information received. All the variety of investigative situations, for example, science is divided into several groups (i.e. typified), which allows you to quickly and correctly determine the optimal direction of the investigation of a criminal case. The versions put forward by the inquiry officer or the investigator presuppose the implementation of a certain set of investigative actions and operationalsearch measures necessary for their verification. This fact also affects their typing. Consequently, there is every reason for identifying typical problems of the investigation, as well as algorithms for the actions of the investigator for their consistent and purposeful solution.

Thus, the theory of forensic science has the necessary prerequisites for improving the methods of investigating crimes. Further development of the theory and practice of algorithmicization and programming of crime investigation will allow researchers to develop universal recommendations of a new generation, specifically designed to manage various investigative situations in the course of investigating crimes that have specific and group similarities. The algorithms and investigation programs themselves will undoubtedly benefit investigators and interrogators in their professional activities.

\section{CONCLUSIONS}

So, the methods of machine learning (artificial intelligence) turned out to be an advanced, modern tool in the field of crime investigation. Our work has shown that these methods can be used to develop effective diagnostic and predictive tools during the investigation of various crimes. Artificial intelligence algorithms and programs may become an integral part of the investigation of crimes. The police must be proactive in understanding the theories of machine learning, artificial intelligence and its usefulness in crime investigations.

\section{REFERENCES}

[1] Smola, Alex and Vishwanathan, S.V.N. (2008), Introduction to Machine Learning, United Kingdom Cambridge University Press. 
[2] Vyugin, V.V. (2018), Matematicheskiye osnovy mashinnogo obucheniya $i$ prognozirovaniya [Mathematical Foundations of Machine Learning and Forecasting], Izdatelstvo MTsNMO, Moskva, Rossija.

[3] Vetrov, D.P. and Kropotov, D.A. (2006), Algoritmy vybora modeley $i$ postroyeniya kollektivnykh resheniy $v$ zadachakh klassifikatsii. osnovannyye na printsipe ustoychivosti [Algorithms for choosing models and constructing collective solutions in classification problems based on the principle of stability], Moskva, Rossija.

[4] Vorontsov, K.V. Matematicheskiye metody obucheniya po pretsedentam (teoriya obucheniya mashin) [Mathematical methods of teaching by precedents (machine learning theory)], available at: http://www.machinelearning.ru/wiki/images/6/6d/ Voron-ML-1.pdf

[5] Mohri, M. and Rostamizadeh, A. (2013), Perceptron Mistake Bounds, available at: https://arxiv.org/pdf/1305.0208.pdf

[6] James, G. Witten, D. Hastie, T. Tibshirani, R. and eds. (2013), An Introduction to Statistical Learning: With Applications in R, Springer, New York, USA.

[7] Hastie, T. Tibshirani, R. and Friedman, J.H. (2009), The Elements of Statistical Learning: Data Mining, Inference, and Prediction, 2nd ed, Springer, New York, USA.

[8] Bishop, C.M. (2006), Pattern Recognition and Machine Learning, Springer, Series: Information Science and Statistics.

[9] Murphy Kevin, P. (2012), Machine Learning: A Probabilistic Perspective, The MIT Press.

[10] Shannon, C.E. (1949), Communication in the presence of noise, Proc. Institute of Radio Engineers, Jan., T. 37, no 1, pp. 10-21.

[11] Gudfellou, Ya. Bendzhio, I. and Kuvill, A. (2017), Glubokoye obucheniye [Deep learning], DMK Press.

[12] Leskovets, Yu. Radzharaman, A. and Ulman, D. (2016), Analiz bolshikh naborov dannykh [Analysis of large datasets], DMK Press.

[13] Kung, S.Y. (2014), Kernel Methods and Machine Learning, Cambridge University Press.

[14] Skansi, S. (2018), Introduction to Deep Learning: From Logical Calculus to Artificial Intelligence, Springer.

[15] Korystin, O.Ye. (2020), Chapter 4. State Legal Police of Scientific Prediction. Public administration in the digital economy, monograph, Tallinn, Scientific Center of Innovative Researches OU, DOI: 10.36690 PADE

[16] Korystin, Oleksandr and Svyrydiuk, Nataliia (2021), "Formation of security competences in law enforcement activities", Nauka i Pravookhorona, vol. $1 \quad(51), \quad$ pp. 191-198 DOI: $10.36486 / \mathrm{np} .2021 .1(51) .20$

[17] Myuller, A. and Gvido, S. (2017), Vvedeniye v mashinnoye obucheniye s pomoshchyu Python [Introduction to Machine Learning with Python], Moskva, Rossija.

[18] Flakh, P. (2015), Mashinnoye obucheniye. Nauka $i$ iskusstvo postroyeniya algoritmov. kotoryye izvlekayut znaniya iz dannykh [Machine learning. The science and art of building algorithms that extract knowledge from data], DMK Press.

[19] Korystin, Oleksandr and Svyrydiuk, Nataliia (2021), "Activities of Illegal Weapons Criminal Component of Hybrid Threats", Proceedings of the International Conference on Economics, Law and Education Research (ELER 2021), vol. 170, 22 March, pp. 86-91, DOI: 10.2991/aebmr.k.210320.016

[20] Korystin, Oleksandr and Svyrydiuk Nataliia (2020), "Methodological principles of risk assessment in law enforcement activity", Nauka $i$ Pravookhorona, vol. 3 (49), pp. 191-198, DOI: $10.36486 / \mathrm{np} .2020 .3(49)$

[21] Hastie, T. Tibshirani, R. and Friedman, J. (2014), The Elements of Statistical Learning, Springer.

[22] Barber, D. (2012), Bayesian Reasoning and Machine Learning, Cambridge University Press.

[23] Mackay, D.J.C. (2003), Information Theory, Inference, and Learning Algorithms, Cambridge University Press.

[24] Smith, J. (2018), Machine Learning Systems, Manning Publications Co.

[25] Samer, I. and Mohamed, Muhamed Abdelhadi (2021), "IoT Bus Navigation System with Optimized Routing using Machine Learning", International Journal of Information Technology and Computer Science, vol. 13, no. 3, pp. 1-15, DOI: 10.5815/ijitcs.2021.03.01

[26] Marina, Azer Mohamed, Taha Hala, H. and Zayed, Mahmoud Gadallah (2021) "Credibility Detection on Twitter News Using Machine Learning Approach", International Journal of Intelligent Systems and Applications, vol. 13, no. 3, pp. 1-10, DOI: $10.5815 /$ ijisa.2021.03.01 
[27] Waheed, G. Gadallah Nagwa, M. Omar and Hosni, M. Ibrahim (2021), "Machine Learning-based Distributed Denial of Service Attacks Detection Technique using New Features in Software-defined Networks", International Journal of Computer Network and Information Security, vol. 13, no. 3, pp. 15-27, DOI: 10.5815/ijcnis.2021.03.02
[28] Muhammad, Yasir Zafi, Sherhan Shah Sajjad, Ali Memon and Zahid, Ali (2021), "Machine Learning Based Analysis of Cellular Spectrum", International Journal of Wireless and Microwave Technologies, vol. 11, no. 2, pp. 24-31, DOI: 10.5815/ijwmt.2021.02.03 